\title{
Roles of Epiluminescence Dermoscopy beyond the Diagnoses of Cutaneous Malignancies and Other Skin Diseases
}

\author{
Antonio Chuh ${ }^{1^{*}}$ \\ ${ }^{1}$ Jockey Club School of Public Health and Primary Care, The Chinese University of Hong Kong, \\ The Prince of Wales Hospital, Sha Tin, Hong Kong.
}

Author's contribution

The sole author designed, analyzed and interpreted and prepared the manuscript.

Article Information

DOI: 10.9734/IJTDH/2017/34851

Editor(s):

(1) Janvier Gasana, Department of Environmental \& Occupational Health, Robert Stempel College of Public Health \& Social Work, Florida International University, USA.

Reviewers:

(1) Bilal Dogan, University of Health Sciences, Istanbul, Turkey.

(2) Renshan Sun, Third Mllitary Medical University, China. Complete Peer review History: http://www.sciencedomain.org/review-history/19745

Clinical Practice Article

Received $15^{\text {th }}$ June 2017

Accepted $23^{\text {rd }}$ June 2017

Published 28 ${ }^{\text {th }}$ June 2017

\begin{abstract}
Epiluminescence dermoscopy was developed mainly for the diagnoses of melanoma and other skin cancers. This technology is also being increasingly applied for the diagnoses of other cutaneous diseases.

With rising popularity and availability, dermoscopes are taking up other roles. We discussed how dermoscopes facilitate education and counselling for patients and parents of patients, modify health-related behaviour, clinical research, and dermoscope-guided operations and procedures.

Keywords: Alopecia areata; cross-polarisation; dermatoscope; surface microscopy; pediculosis pubis; pseudofolliculitis barbae.

\section{INTRODUCTION}

Epiluminescence dermoscopy been developed mainly for the and diagnosis of melanoma,

(ED) has assessment melanocytic

naevi, and other cutaneous cancers. The diagnoses of other skin diseases are also facilitated by ED [1-3]. We report here roles of ED beyond clinical diagnoses of skin diseases.
\end{abstract}




\subsection{Education and Counselling for Patients}

\subsubsection{Patient 1}

We have previously reported a 40-year-old male consulting us for painful eruptions over his chin [4]. He was obsessed with his hygiene, and was holding his skin tight with his fingers and shaving hard with triple-bladed razors to "remove the dirt and germs" daily. Upon physical examination, we diagnosed pseudofolliculitis barbae and hypertrophic scars.

We advised the patient to use electric shavers. However, he refused to accept our diagnosis and advices. We then performed digital epiluminescence dermoscopy (DED), and showed him images of reverted U-shaped ingrown hairs due to over-enthusiastic shaving. He exhibited a complete attitude change, and complied with our recommendations to use electric razors, not to holding the skin taut while shaving, and to allow a no-shaving buffer of three days every fortnight. The disease completely remitted in four weeks.

\subsubsection{Patient 2}

A 57-year-old male had been suffering from generalised pruritus for more than three months. He was indulging himself with two hot baths applying soap bars every day. He never applied emollients, and was scratching himself constantly.

Upon physical examination, we diagnosed asteatotic dermatitis with nodular prurigo and impetiginisation (Figs. $1 \mathrm{a}$ and 1b). We recommended emollients, but the patient demanded just topical corticosteroids from us, which was previously and repeatedly prescribed by his general practitioner.

We showed him Figs. 2a and 2b, taken with dermoscope without and with cross-polarisation respectively. We explained that although inflammation was not seen by naked eyes or a scope with magnification (Fig. 2a), inflammation was serious in the deeper layers at around the dermo-epidermal junction (Fig. 2b).

The patient accepted our diagnoses. We recommended body lotions instead of soap bars, and emollients to be applied generously after his baths. We prescribed a five-day course of cefuroxime $250 \mathrm{mg}$ twice daily, and $0.025 \%$ fluocinolone with $0.5 \%$ neomycin cream to be applied to the indurated areas. Remarkable remissions in symptoms and signs were noted when he attended follow-up three weeks later.

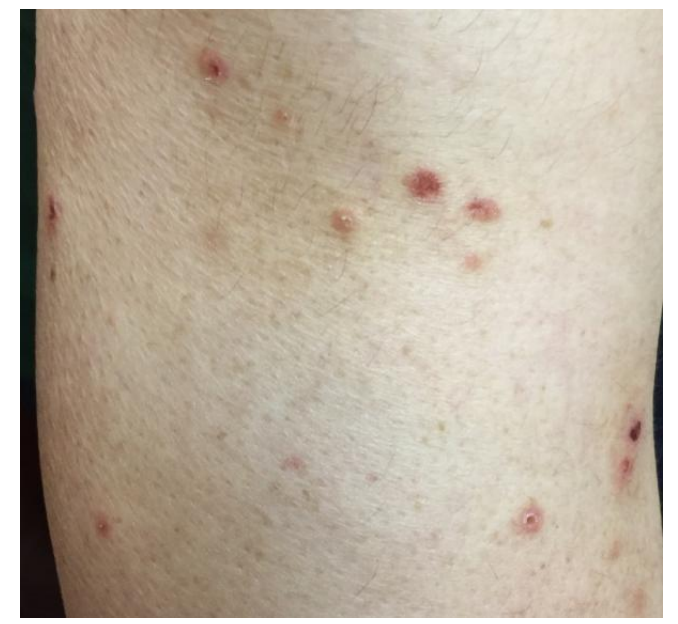

Fig. 1a. Erythematous and excoriating lesions in a male patient with asteatotic dermatitis and nodular prurigo

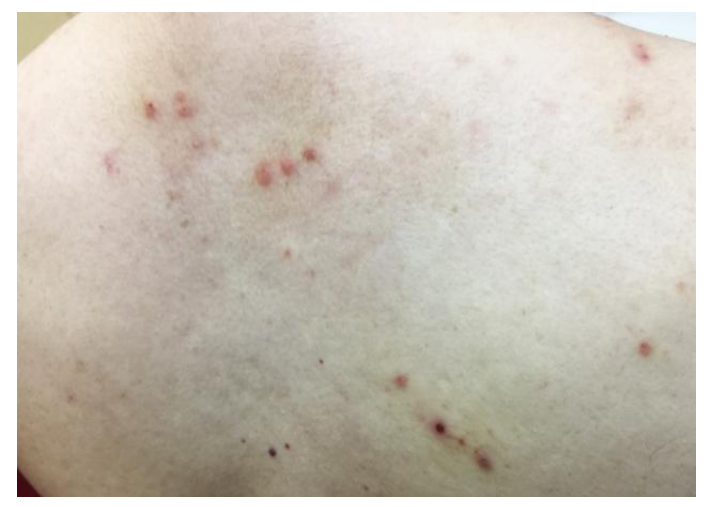

Fig. 1b. Similar lesions on his upper back

\subsubsection{Patient 3}

A 35-year-old female was referred to us for three-month history of multiple lesions of alopecia areata. No lesion was present in the occipital region. Other hairs including such in the genital regions were unaffected. Fig. 3a depicts the central part of the largest lesion on the vertex. We could not identify an exclamation-mark in this image. However, we noted two hairs having turned from black and thick (arrowed in blue) to silvery-white and thin (arrowed in red).

Other than prescribing the appropriate treatments for her, we spent much time talking to her about the generally good prognosis of alopecia areata. We also kept all of her 
dermoscopic images. Four months later, we took Fig. $3 b$ which was in the vicinity of Fig. $3 a$. Much improvement was seen. Although other lesions were still showing no remission, we convinced her that the activity of this organ-specific autoimmune disease was sinking, as evidenced by her sequential dermoscopic images.
Throughout these months, although the patient was enduring an inevitable phase of depression, she could still continue her work as a company secretary. Through viewing ED images with us, she kept on hoping for complete disease remission, which did happen another four months later.

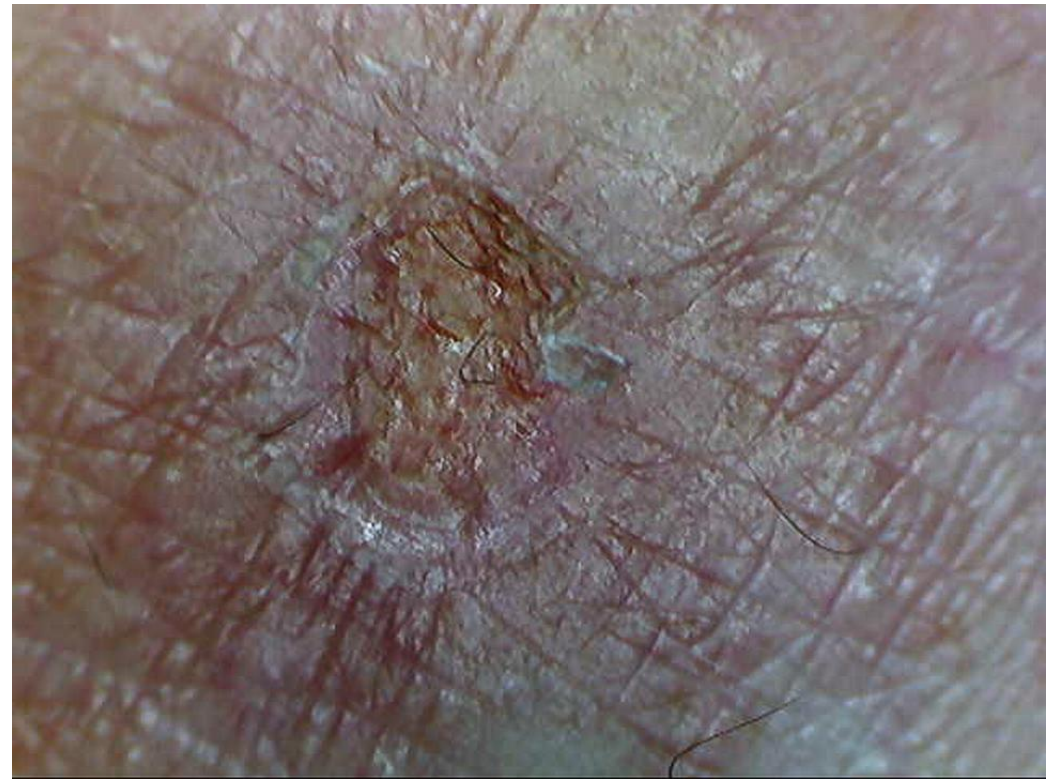

Fig. 2a. Image of one lesion of the patient with asteatotic dermatitis and nodular prurigo, taken by dermoscopy without cross-polarisation. Some inflammation was seen

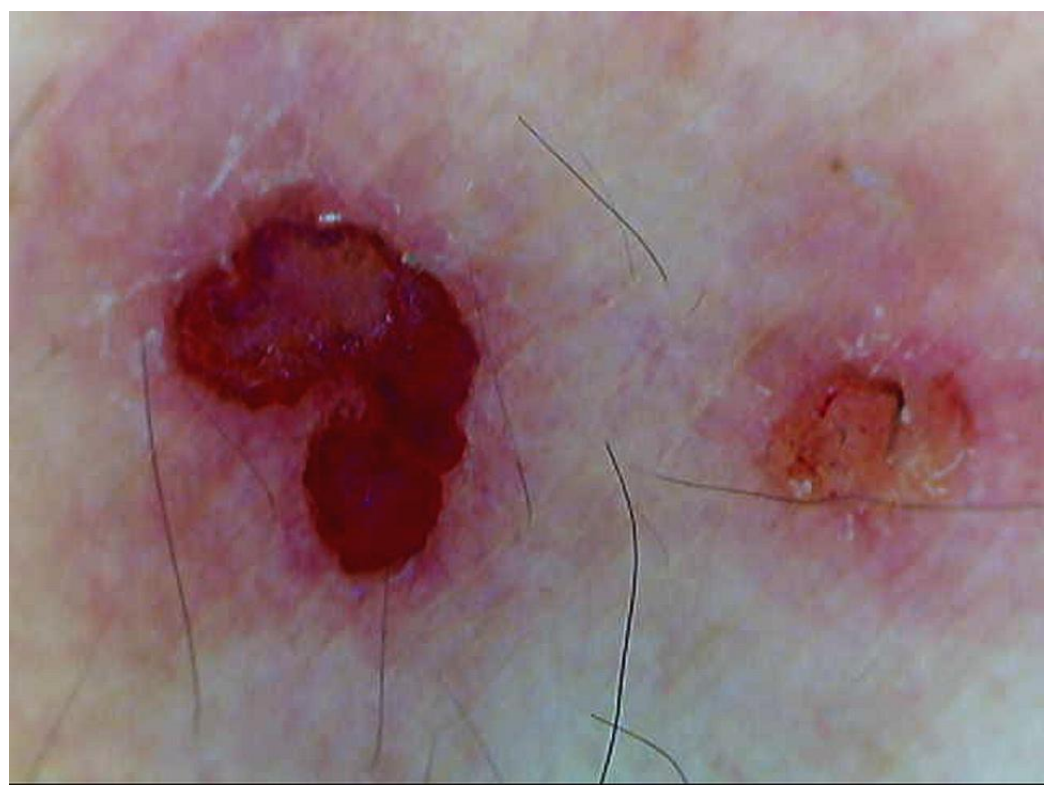

Fig. 2b. Image of lesions taken by epiluminescence dermoscopy, demonstrating that the inflammation was deep and serious 


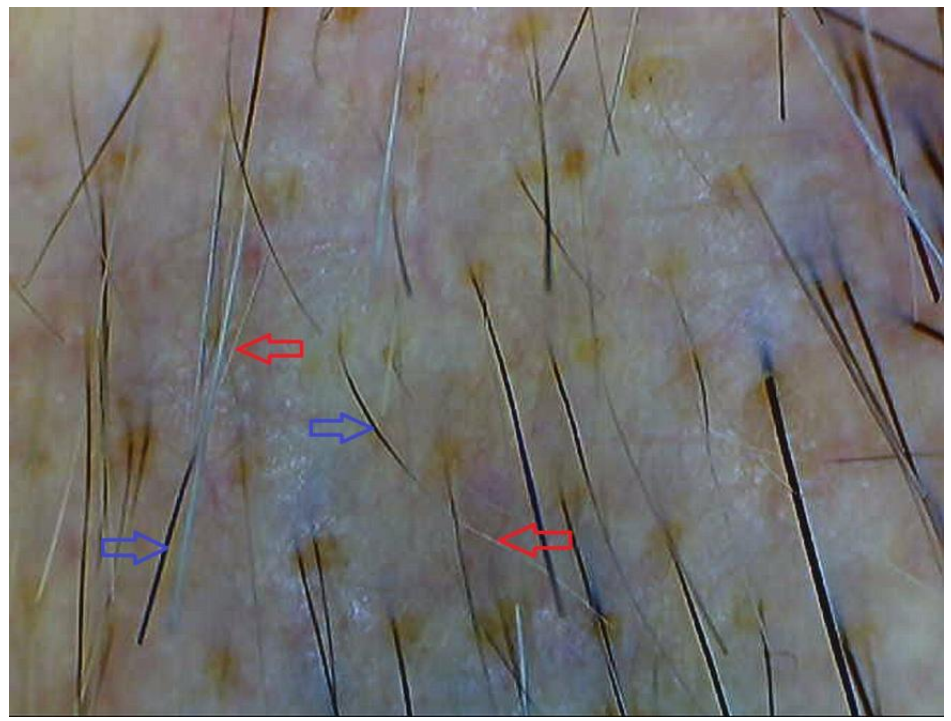

Fig. 3a. Dermoscopic image of a lesion on the scalp of a patient with alopecia areata. The disease was progressing as previously thick and dark hairs (arrowed in blue) were turning into thin and grey ones (arrowed in red)

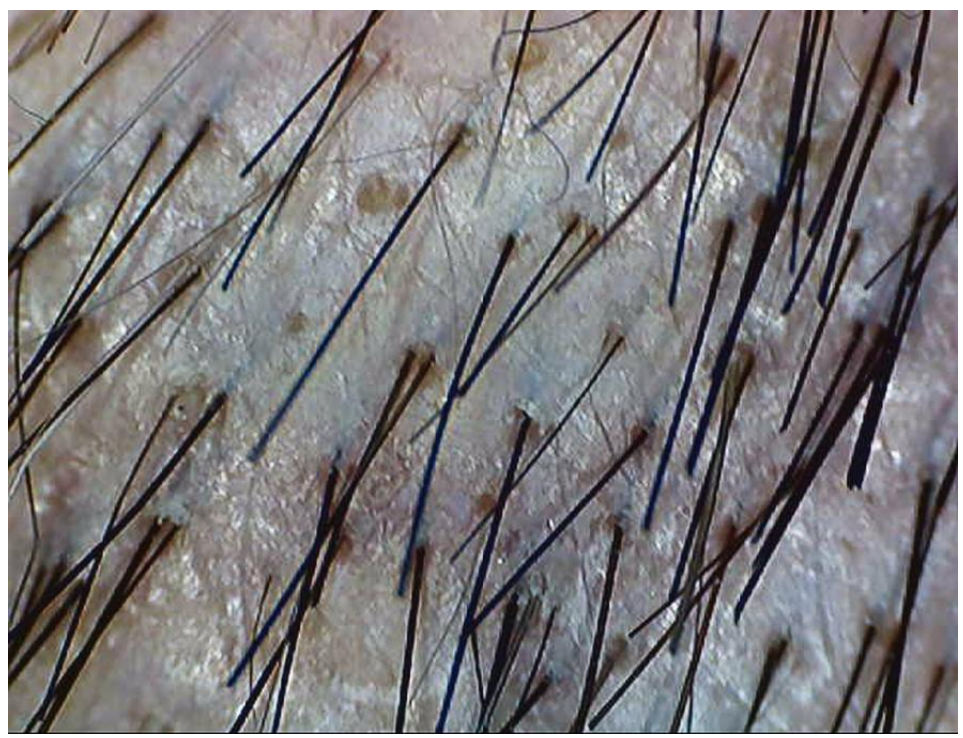

Fig. 3b. Thicker and darker hairs depicted by dermoscopy four months later, depicting that the disease was becoming less active

\section{MODIFYING} BEHAVIOUR

A 40-year-old male consulted us for pruritus in the genital region. He had history of Chlamydia trachomatis serovars $\mathrm{D}-\mathrm{K}$ infection and genital human papillomavirus infection. He was heterosexual, and was having multiple sex partners.

\section{HEALTH-RELATED}

Examination with DED revealed multiple nits (Fig. 4), although no adult of Pthirus pubis was visualised. We showed the patient this image. Being confronted with such alarming image, and having realised that condoms offer less protection for pediculosis pubis infestation than for C. trachomatis serovars D-K and Neisseria gonorrhoea infections, he was convinced that his sexual behaviour should change for the better. 


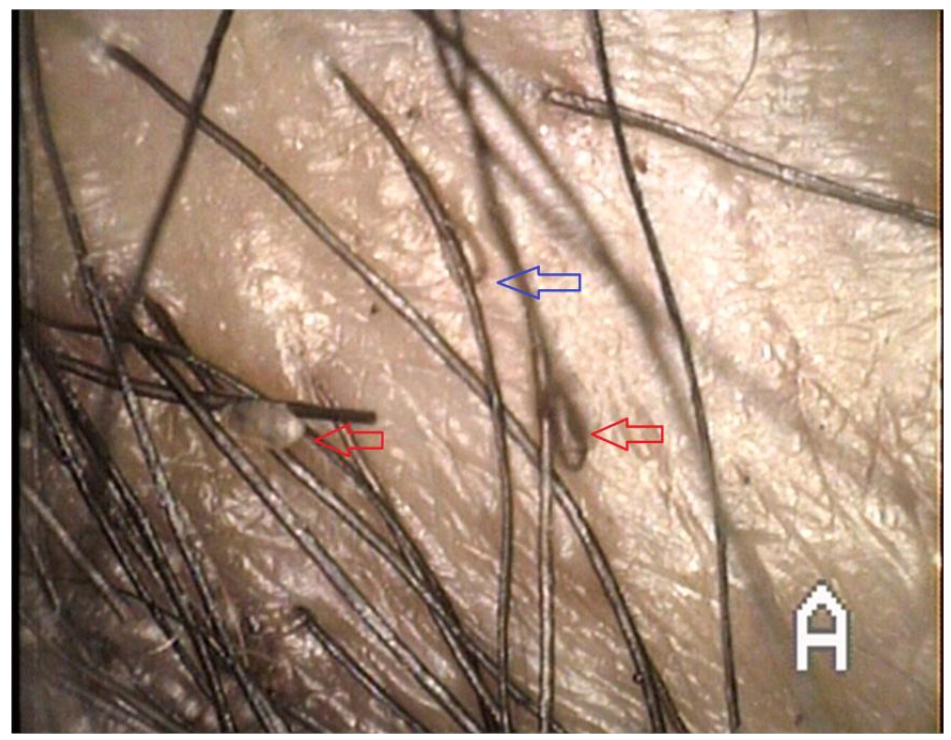

Fig. 4. Dermoscopic image of the genital region near the root of the penis of a patient, showing nits of Pthirus pubis. Two viable nits are arrowed in red. One empty nit is arrowed in blue

\section{EDUCATION FOR HEALTHCARE PROFESSIONALS}

While taking medical students with us in our clinics, medical students found themselves fascinated by the extent of dermatological features and signs in DED images which they could view concomitantly as we examined our patients. This is one form of problem-based learning, which would arouse situation interest in their active educational process [5].

We had a crude model of the skin with us (Fig. 5). Twelve levels of cross-polarising were available for our DED. We would explain to the students that "we are now viewing deeper into the subdermal region, where features of panniculitis should be seen for this lady with erythema nodosum" This is a lot more interesting than a histopathological figure. When attending us again, students would be fluent in discussing with us the histology of the skin, and meanings of basic histopathological features of skin diseases such as spongiosis or parakeratosis.

We expect our students to have basic knowledge of the histology and histopathology of the skin when the students had finished their attachment with us. This could be dry and boring. In stark contrast, when we portray that ED images are a bridge between histopathology and clinical signs (Table 1), students would be delighted to learn deeper, literally and figuratively. By the end of the attachment, most students would request us to allow them to scope the skin of patients by themselves.

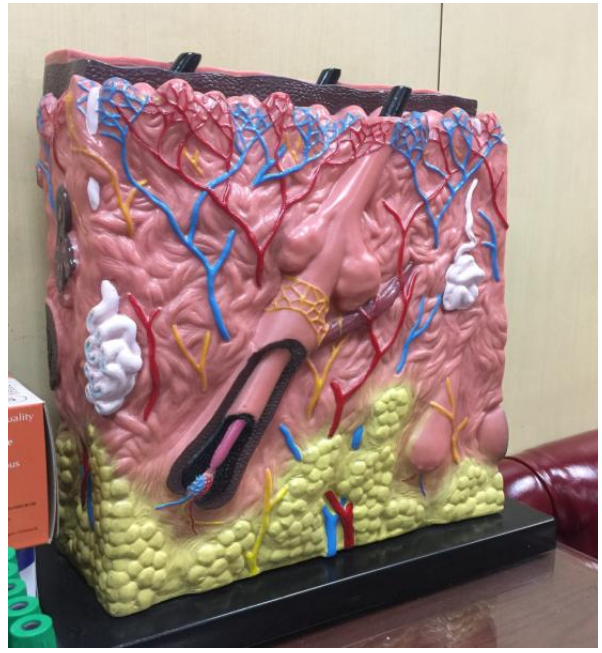

Fig. 5. A simple and inexpensive model of the skin. Coupled with digital epiluminescence dermoscopic images taken in different layers of the skin, this model would enhance students in understanding histology of the skin and histopathologies of skin diseases

We would also share ED images to physicians in various stages of specialisation, and paramedical professionals such as nursing students taking electives in skin diseases. Moreover, data banks for ED images are being kept by us and other institutions, mainly for postgraduate education and research. 
Table 1. Comparison of the three modalities to skin examination for non-cancer skin diseases

\begin{tabular}{|c|c|c|c|}
\hline & $\begin{array}{l}\text { Physical examination by naked } \\
\text { eyes }\end{array}$ & Epiluminescence dermoscopy & Lesional biopsy for histopathology \\
\hline Applicability for skin diseases & All skin diseases & Still in active explorations & $\begin{array}{l}\text { Histopathological features are non- } \\
\text { specific to some skin diseases. }\end{array}$ \\
\hline Magnification & $1 \mathrm{X}$ & $8 X-50 X$ & $10 \mathrm{X}-800 \mathrm{x}$ \\
\hline Depth of examination & Skin surface & Skin surface to sub-dermal fat & Stratum corneum to sub-dermal fat \\
\hline Cost for setting up & Nil & $100-5000$ USD & Nil \\
\hline Cost per examination & $\mathrm{Nil}$ & Nil & $20-200$ USD \\
\hline $\begin{array}{l}\text { Specific training for the } \\
\text { clinicians }\end{array}$ & Nil & Additional training necessary & Nil \\
\hline Time for the examination & In minutes for most circumstances & $\begin{array}{l}\text { Probably a little longer than for naked } \\
\text { eyes }\end{array}$ & At least $20-30$ minutes \\
\hline Time needed for result & Immediate & Immediate & Four to ten days \\
\hline Can patients see the image? & Yes & Depends on the settings of the facility & No \\
\hline Risk of cross-infectivity & $\begin{array}{l}\text { Negligible if clinicians wash their } \\
\text { hands after any examination }\end{array}$ & $\begin{array}{l}\text { Yes. Disinfection, sterilisation, or using } \\
\text { disposable dermoscopic heads will } \\
\text { minimise such. }\end{array}$ & $\begin{array}{l}\text { Yes. Sterilisation is necessary for all } \\
\text { equipments used. }\end{array}$ \\
\hline Discomfort for patients & Negligible & $\begin{array}{l}\text { Negligible apart for infants and young } \\
\text { children }\end{array}$ & Yes. \\
\hline Complications & No & No & $\begin{array}{l}\text { Infection and bleeding on the biopsy } \\
\text { site }\end{array}$ \\
\hline Leaving a scar & No & No & Yes. \\
\hline $\begin{array}{l}\text { Further possible } \\
\text { enhancements }\end{array}$ & $\begin{array}{l}\text { Magnifying glass, diascopy, } \\
\text { examination under Wood's light }\end{array}$ & $\begin{array}{l}\text { Adjustment for the levels of cross- } \\
\text { polarisations, adapters and lens for higher } \\
\text { magnifications, adapters to connect to } \\
\text { cameras and video-cameras }\end{array}$ & $\begin{array}{l}\text { Direct immunofluorescence, } \\
\text { immunohistochemical staining, in-situ } \\
\text { hybridisation }\end{array}$ \\
\hline $\begin{array}{l}\text { Possible developments in the } \\
\text { future }\end{array}$ & $\begin{array}{l}\text { New clinical signs will be discovered } \\
\text { for new diseases. Diagnostic criteria } \\
\text { for some skin diseases. Evidence- } \\
\text { based studies to substantiate or } \\
\text { rectify validities and reliability of } \\
\text { clinical signs. }\end{array}$ & $\begin{array}{l}\text { More explorations for dermoscopic } \\
\text { diagnoses for non-cancer skin diseases. } \\
\text { Dermoscope-guided skin operations. } \\
\text { Computer storage and comparison with } \\
\text { appearances of previous lesions. }\end{array}$ & $\begin{array}{l}\text { Technical developments to increase } \\
\text { the validity and reliability of the } \\
\text { findings. Algorithms for } \\
\text { histopathological features }\end{array}$ \\
\hline
\end{tabular}




\section{RESEARCH}

ED has been reported to be applicable in diagnosing and assessing a wide range of diseases beyond melanomas and cutaneous malignancies [1-3]. Variants of ED have also been utilised to examine diseases of the hairs [6-8], nails [6,9,10], and capillaries [9]. The range of research involving ED is thus extremely wide. We hereby quote several specific arenas.

The first would been for diagnosis and diagnostic criteria of skin diseases. We have previously reported on the clinical [11] and technological [12] aspects of visualising peripheral collarette scaling in pityriasis rosea by ED. We then proceeded to establish and validate a set of diagnostic criteria for this paraviral exanthem $[13,14]$. During this process, we have seriously considered incorporating ED findings as part of the diagnostic criteria. However, we based our decisions on evidence. Our quantitative analyses including sub-group analyses and meta-analyses indicated that the inclusion of ED findings would be helpful for several sub-groups such as children with pityriasis rosea and some variants of pityriasis rosea $[15,16]$. The sensitivity, specificity, and positive and negative predictive values as a whole were not elevated if ED findings were incorporated as part of the criteria [17].

We thus deliberated not to incorporate ED in our diagnostic criteria for pityriasis rosea. However, as ED is being applied to many cutaneous ailments, other investigators would incorporate ED findings into diagnostic criteria of other skin diseases. Many dermoscopic features have, for example, been described for alopecia areata [18-20].

Another role is that ED might facilitate investigations on pathogenesis of skin diseases, and improve outcomes of treatments directly. One example would be focal vitiligo. It is known that there exists two reservoirs of melanocytes on our skin - perifollicular and interfollicular $[21,22]$. The immunopathogenesis of focal vitiligo is incompletely known. For some reasons, the organ-specific or tissue-specific autoimmunity attacks the interfollicular reservoir of melanocytes first, before attacking the perifollicular reservoirs [21,22].

Should this immunopathogenesis be true, it would be expected that a zone would exist with spots of pigmentation around hair follicles. Such pattern has indeed been found macroscopically.
We discovered and reported for the first time the visualisation of such pattern at the dermoscopic magnification level [23]. We then further reported that identification of such zones by ED could enhance the localisation of regions with high autoimmune activity, and hastened efficacy of drug treatments [24].

The third scenario is that punch biopsy for confirmation of compatible histopathology needs to be performed as an inclusion criteria in some studies. Three issues arise here. Firstly, histopathological features in skin biopsies are often non-specific, and could only substantiate, but not confirm, a diagnosis. A list of differential diagnoses should therefore be delivered to the pathologist. Secondly, research plans which need clinically unnecessary invasive procedures might incur higher thresholds to pass ethics approval. Lastly, patients or parents of patients would decline the invasive procedure of a punch biopsy merely for clinical research.

The utilisation of ED could solve some of these problems. If dermoscopic findings are characteristic enough to confirm, or strongly substantiate, a diagnosis, punch biopsies would become unnecessary in some circumstances. The ethics committee would then approve the research protocol, and the study or control subjects would be a lot willing to be recruited in the study which require a gentle touch of a dermoscopic head only.

In other words, if our understandings of dermoscopic findings are adequate enough, these findings could be integrated to the inclusional or exclusional criteria for the recruitment of study and control subjects, in observational studies as well as in interventional trials.

\section{DERMOSCOPE-GUIDED OPERATIONS}

Many medical and surgical procedures are being guided by imaging equipments. Instrumental guidance increases the chance of accurate attainment, removal, or destruction of body cells, tissues, or organs. For skin cancers, Mohs surgeries maximise the cure rate, minimise the recurrence rates, and provide good cosmetic results. ED is being used by many clinicians in various parts of Mohs surgeries [25-27]. This per se is adequate substantiation for the applicability of ED in skin procedures.

However, many clinicians performing skin operations for cancer or other diseases might not 


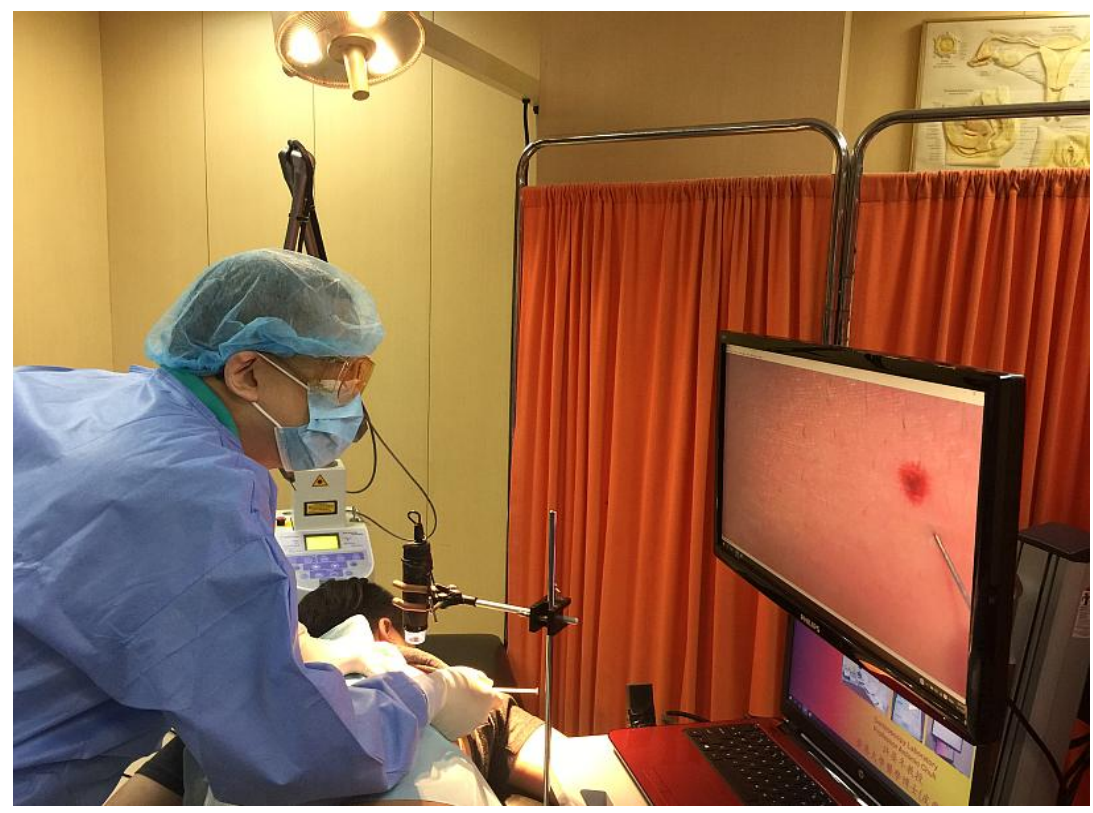

Fig. 6. The author (left) performing dermoscopy-guided carbon dioxide laser ablation of a junctional/compound melanocytic naevus

have adequate support to conduct Mohs surgery. At the very least, an in situ pathologist might not be present in their medical facilities. With the availability of robust but accurate dermoscopic systems, delicate procedures can be done on the skin under instrumental guidance (Fig. 6).

The skin is skin-deep. The threshold of dermoscope-guided operations is thus substantively lower than such of operations in general surgery, neurosurgery, or gynaecology. If something goes wrong in a laparoscopic cholecystectomy, a switch to laparotomy might be indicated. If the dermoscope goes wrong in a dermatoscope-guided operation, the clinician might merely switch his eyesight from the monitor to the patient and proceed with the operation smoothly. Dermoscopy is commencing to be applied to a wide range of surgical procedures for skin diseases [28-30].

However, as for the introduction of any medical or surgical procedure, we should be constantly aware of training of clinicians and the assisting staff, and limitations of the guiding and cutting equipments.

\section{CONCLUDING REMARKS}

Apart from clinical applications to diagnose melanomas, other skin cancers, and other skin diseases, ED could play active roles in educating patients, modifying health-related behaviours such as sexual behaviour, education of medical students and other healthcare professionals in training, and clinical research. ED-guided procedures and operations present new frontiers to achieve higher precisions and lower risk of complications. However, clinicians should be aware of their own training and experience to proceed in wider applications of ED, and that all equipments are under regular and proper maintenance to tackle these tasks.

\section{CONSENT}

As per international standard or university standard, patient's written consent has been collected and preserved by the author.

\section{ETHICAL APPROVAL}

It is not applicable.

\section{COMPETING INTERESTS}

Author has declared that no competing interests exist.

\section{REFERENCES}

1. Cinotti E, Labeille B, Cambazard F, Perrot JL. Confocal microscopy for special sites and special uses. Dermatol Clin. 2016; 34(4):477-485.

DOI: $10.1016 / j . d e t .2016 .05 .010$ 
2. Errichetti E, Stinco G. Dermoscopy in general dermatology: a practical overview. Dermatol Ther (Heidelb). 2016;6(4):471507. Epub 2016 Sep 9.

3. Hibler BP, Qi Q, Rossi AM. Current state of imaging in dermatology. Semin Cutan Med Surg. 2016;35(1):2-8.

DOI: 10.12788/j.sder.2016.001

4. Chuh A, Zawar V. Epiluminescence dermatoscopy enhanced patient compliance and achieved treatment success in pseudofolliculitis barbae. Australas J Dermatol. 2006;47(1):60-62.

5. Schmidt HG, Rotgans JI, Yew EH. The process of problem-based learning: what works and why. Med Educ. 2011;45(8): 792-806.

DOI: 10.1111/j.1365-2923.2011.04035.x

6. Miteva M, Tosti A. Hair and scalp dermatoscopy. J Am Acad Dermatol. 2012; 67(5):1040-1048.

10.1016/j.jaad.2012.02.013.

7. Guttikonda AS, Aruna C, Ramamurthy DV, Sridevi K, Alagappan SK. Evaluation of clinical significance of dermoscopy in alopecia areata. Indian J Dermatol 2016; 61(6):628-633.

8. Castelo-Soccio L. Diagnosis and management of hair loss in children. Curr Opin Pediatr. 2016;28(4):483-489.

DOI: 10.1097/MOP.0000000000000376

9. Hughes M, Moore T, O'Leary N, Tracey A, Ennis H, Dinsdale G, Murray A, Roberts C, Herrick AL. A study comparing videocapillaroscopy and dermoscopy in the assessment of nailfold capillaries in patients with systemic sclerosis-spectrum disorders. Rheumatology (Oxford). 2015; 54:1435-1442.

10. Kok WL, Lee JS, Chio MT. Subungual squamous cell carcinoma: the diagnostic challenge and clinical pearls. Case Rep Dermatol. 2016;8(3):272-277.

11. Chuh AA. Collarette scaling in pityriasis rosea demonstrated by digital epiluminescence dermatoscopy. Australas J Dermatol. 2001;42(4):288-290.

12. Chuh AA. The use of digital epiluminescence dermatoscopy to identify peripheral scaling in pityriasis rosea. Comput Med Imaging Graph. 2002;26(2): 129-134.

13. Chuh AA. Diagnostic criteria for pityriasis rosea: a prospective case control study for assessment of validity. J Eur Acad Dermatol Venereol. 2003;17(1):101103.
14. Zawar V, Chuh A. Applicability of proposed diagnostic criteria of pityriasis rosea: results of a prospective case-control study in India. Indian J Dermatol. 2013;58(6): 439-442.

DOI: 10.4103/0019-5154.119950

15. Chuh A, Zawar V, Lee A. Atypical presentations of pityriasis rosea: Case presentations. J Eur Acad Dermatol Venereol. 2005;19(1):120-126.

16. Zawar V, Chuh A. Follicular pityriasis rosea. A case report and a new classification of clinical variants of the disease. J Dermatol Case Rep. 2012;6(2): 36-39.

DOI: 10.3315/jdcr.2012.1095

17. Chuh A, Zawar V, Sciallis GF, Lee A. The diagnostic criteria of pityriasis rosea and Gianotti-Crosti syndrome - a protocol to establish diagnostic criteria of skin diseases. J R Coll Physicians Edinb. 2015; 45(3):218-225.

DOI: 10.4997/JRCPE.2015.310

18. Guttikonda AS, Aruna C, Ramamurthy DV, Sridevi K, Alagappan SK. Evaluation of clinical significance of dermoscopy in alopecia areata. Indian J Dermatol. 2016; 61(6):628-633.

19. Jang YH, Moon SY, Lee WJ, Lee SJ, Lee WK, Park BC, Kim H, Kim DW. Alopecia Areata Progression Index, a scoring system for evaluating overall hair loss activity in alopecia areata patients with pigmented hair: A development and reliability assessment. Dermatology. 2016; 232(2):143-9.

DOI: $10.1159 / 000442816$

20. Jha AK, Udayan UK, Roy PK, Amar AKJ, Chaudhary RKP. Dermoscopy of alopecia areata-a retrospective analysis. Dermatol Pract Concept. 2017;7(2):53-57.

DOI: $10.5826 /$ dpc.0702a12

21. Taïeb A. Intrinsic and extrinsic pathomechanisms in vitiligo. Pigment Cell Res. 2000;13Suppl 8:41-47.

22. Petit L, Claudine, Piérard-Franchimont, Saint Léger D, Loussouarn G, Piérard GE. Subclinical speckled perifollicular melanosis of the scalp. Eur J Dermatol. 2002;12(6):565-568.

23. Chuh AA, Zawar V. Demonstration of residual perifollicular pigmentation in localized vitiligo - a reverse and novel application of digital epiluminescence dermoscopy. Comput Med Imaging Graph. 2004;28(4):213-217. 
24. Chuh A. A report on applying digital epiluminescence dermoscopy to guide topical treatment for generalised vitiligo. Int J Trop Dis Health 2017;16:(in press).

25. Suzuki HS, Serafini SZ, Sato MS. Utility of dermoscopy for demarcation of surgical margins in Mohs micrographic surgery. An Bras Dermatol. 2014;89(1):38-43.

DOI: 10.1590/abd1806-4841.20142400

26. Jawed SI, Goldberg LH, Wang SQ. Dermoscopy to identify biopsy sites before Mohs surgery. Dermatol Surg. 2014;40(3): 334-337.

DOI: $10.1111 /$ dsu.12422

27. Yeom SD, Lee SH, Ko HS, Chung KY, Shin J, Choi GS, Byun JW. Effectiveness of dermoscopy in Mohs micrographic surgery (MMS) for nonmelanoma skin cancer (NMSC). Int J Dermatol. 2017; 56(6):e136-e139.

DOI: $10.1111 / \mathrm{ijd} .13501$
28. Pinheiro $R$, Oliveira $A$, Mendes-Bastos $P$. Dermoscopic and reflectance confocal microscopic presentation of relapsing eccrine porocarcinoma. J Am Acad Dermatol. 2017;76(2S1):S73-S75.

DOI: 10.1016/j.jaad.2016.08.020

29. Lallas A, Apalla Z, loannides D, Lazaridou E, Kyrgidi A, Broganelli P, Alfano R, Zalaudek I, Argenziano G; International Dermoscopy Society. Update on dermoscopy of Spitz/Reed naevi and management guidelines by the International Dermoscopy Society. $\mathrm{Br} \mathrm{J}$ Dermatol. 2017. (Epub ahead of print) DOI: $10.1111 /$ bjd.15339

30. Furlan KC, Kakizaki P, Chartuni JCN, Sittart JA, Valente NYS. Hidroacanthoma simplex: dermoscopy and cryosurgery treatment. An Bras Dermatol. 2017;92(2): 253-255.

DOI: 10.1590/abd1806-4841.20174883

(c) 2017 Chuh; This is an Open Access article distributed under the terms of the Creative Commons Attribution License (http://creativecommons.org/licenses/by/4.0), which permits unrestricted use, distribution, and reproduction in any medium, provided the original work is properly cited. 